\title{
AN ECO-TONE OF CULTURES WHERE THE EDGE EFFECT IS THE VICTIMISATION OF DAMSELS
}

\author{
Meet Singh ${ }^{1}$ and Dr. Monika Kannan ${ }^{2}$ \\ ${ }^{1}$ Research Scholar, Sophia Girls' College (Autonomous), Ajmer, Rajasthan, India \\ ${ }^{2}$ Associate Professor \& Head Department of Geography, Sophia Girls' College (Autonomous), Ajmer, \\ Rajasthan, India
}

DOI: 10.46609/IJSSER.2021.v06i02.002 URL: https://doi.org/10.46609/IJSSER.2021.v06i02.002

\begin{abstract}
A cycle of Deprivation may be linked to monetary resources, however, there is a conflict zone in Tonk district of Rajasthan, where the deprivation is present due to the environment created by patriarchal pressure groups who are not willing to do any work but only want to live a sumptuous life. These factions have created irrelevant and illogical community laws that force women into a never-ending loop of struggles synonymous with different responsibilities, such as 'Khilyawadi women.' A Woman who earns money primarily from sex work to raise the whole family. And this scheme has its roots in the 'Chaari custom'. This is the apparatus under which on the one side, unmarried female members have to feed other family members while on the other side, this structure also involves marriage and woman trade partnerships in which the kanjar community provides women to the Nat community in return for money. Chaari is synonymous with a girl's monetary worth.
\end{abstract}

Keywords: Cycle of Deprivation, Khilyawadi women, Chaari custom, Sex work, etc.

\section{Introduction}

'Jaane Kya Dikh Jaye' (You do not know what you may see) is the catchline of the Rajasthan tourism's digital marketing display. Lakhs'of tourists come to Rajasthan to capture magnificent palaces, colourful costumes, deserts and historical sites in their memories. However, behind this glitter, one veracity is hidden that is girls and women are forced here directly or indirectly by their families in Sex trafficking. Eco-tone is the convergence zone between various culturalethnic ecosystems. This study is focused on the transition zone created by the acculturation of two social groups, the Nat and the Kanjar societies of the Tonk district of Rajasthan with many other cultures through sexual interactions and the abduction of minor girls. As Supreme Court outlined in Kesvananda Bharti judgement that the fundamental rights are the basic features of the Indian constitution. And Article 21 under part third reads as "No person shall be deprived of his 


\section{International Journal of Social Science and Economic Research}

ISSN: $2455-8834$

Volume:06, Issue:02 "February 2021"

or her life or personal liberty except in accordance with the procedure laid down by law". This right is seen as the core of the constitution, the most organic in our living constitution, the foundation of our rules and regulations. The Indian Constitution provides for a range of basic provisions that ensure equal and dignified development for all citizens of India.

In 2015, India, along with other members of the United Nations, adopted the 2030 Agenda for Sustainable Development. The Indian Government has made intense efforts to bring relief to the underprivileged population of the country through the WTO Trade Facilitation Agreement under the Amber Box Subsidy to provide the social welfare benefits of the National Food Security Act 2013. Even after all these efforts, the Kanjar and Nat Communities along with other groups continued trampled down. They remained unable to create socio-economic norms that would provide a decent job for community girls and women to live a dignified life. Every strategic solution to any social issue requires active community engagement. What happens when the societies themselves are the transgressors?

An Operation Gudia conducted by Zee Rajasthan (News channel), unveiled the Human trafficking value chain of the kanjar community of Rajasthan and it is linked not only with other communities within Rajasthan but also spread across states of UP, Haryana, and Madhya Pradesh. In various tv interviews, victims and Police officials revealed the following aspects of human trafficking such as the kidnapping of minors from various regions of north India, the trade of girls within communities on stamp papers, the use of growth hormonal medications, sex businesses run by these communities in various parts of Rajasthan, etc (Mittal, 2019). Edge effects are changes in demographic or group dynamics that exist at the boundary between two or more populations. In this case, the Edge effect is the victimisation of young and marginalized girls and women. The ecological niche of girls and women is of immense importance to the Nat and Kanjar groups since they are Khilyawadis. And the Khilyawadis are the family's primary earning members. Young girls of the Kanjar clan, a nomadic tribe in Rajasthan, are coerced into prostitution by their parents before they reach adulthood, an exploitative practise that the authorities are now taking up against. Under the age-old custom of 'Chaari Pratha,' parents sell off their daughters for lakhs of ropes and often even borrow them for a fixed period. (Press Trust of India, 2016).

"Discussions with Kaje/Kallme (customers or outsiders) who use to go to such villages, underscored one fact that Corona time is the ideal moment for them, because they've never noticed such kind of beautiful ladies accessible for intercourse in such locations."

During the complete lockdown of the COVID 19 pandemic in India, on the one side, the reverse migrant workers from all over India started working by opting alternate jobs either in their agricultural fields, as street vendors, or in MGNREGA. Dance Bar Migrant girls restarted sex 


\section{International Journal of Social Science and Economic Research}

ISSN: $2455-8834$

Volume:06, Issue:02 "February 2021"

work in their permanent residences in the Tonk district of Rajasthan. This is because they were either not competent and confident enough to undertake other works or the constraints enforced by the interest groups of the society.

The Nat Group claims to be the descendants of Rajput, the rulers of Rajputana, may face a crisis linked to their ethnic origin. This is because almost half of their women are sex workers who cannot marry in the Nat caste, and religiously they are allowed to have children without marriage from non-Nat customers. The institution of ghar Janmai socially permits a male of any caste or religion not only to be the client but also to establish a relationship with Nat FSW for a long duration, like a husband. During this period, she remains as the wife of a ghar Janmai and is supposed to confine her sexual contact to him alone. It is expected to satisfy the economic needs of a Nat FSW-turned-wife and her family members. The presence of a biological father over a social rational father, through both positions, is supplemented by a maternal uncle of children born to a Nat female sex workerand a male non-Nat belonging to other castes and religions.As the Nat Females in Dhandha do not marry, at the end of the day the Nat boys embrace girls for their marriage from an analogous Kanjar community. With the marriage alliances of the Nat and Kanjar castes, a growing number of Kanjar women mainly other than those married to Nat, are becoming FSWs and migrating to Dhandha. Kanjar girls are accepted as daughters-in-law, but Nat does not marry kanjar boys from their daughters because they are considered lower in the social hierarchy. The endogamy of caste in the Nat is vanishing. The clan remains exogamous to the dowry, much as the price of the bride is practiced among the Nat. In comparison to the births of FSWs, infants born into the nuptial relations of Nat males with kanjar females outnumbered those born of Natasals (where both husband and wife are Nat). As a result, there is a growing number of births from non-Nat fathers and FSW mothers, as well as from Nat fathers and Kanjar mothers.; A decreasing number of children born from real (asal) Nat husband with Nat wives is leading to an identity crisis of the Nat caste. (Lucas, 2007).

\section{Study region}

The district of Tonk stretches to a geographic region of 7,194 square kilometres and It is ranked 18th in Rajasthan and 125th in India. It lies at $26^{\circ} 17^{\prime} \mathrm{N}$ latitude, $75^{\circ} 78^{\prime} \mathrm{E}$ longitude and $289 \mathrm{~m}$ altitude. It is bounded by the district of Jaipur in the North, the district of Sawai Madhopur in the East, the district of Kota in the South-East, the district of Bundi in the South, the district of Bhilwara in the South-West, and the district of Ajmer in the West. It's located on the 12th National Highway. The actual rainfall in the district amounted to $593.3 \mathrm{~mm}$ in the year 2015-16. According to data reported in 2015, 2.34\% of the total geographical area of the district is occupied by the forest. Administratively, the district is divided into eight Tehsils namely Deoli, Dooni, Malpura, Todaraisingh, Tonk, Uniara, Niwai and Peeplu. Moreover, it has 8 towns and 1,183 villages. The percentage of Scheduled Caste is $2.36 \%$. The scheduled tribe population is 


\section{International Journal of Social Science and Economic Research}

ISSN: $2455-8834$

Volume:06, Issue:02 "February 2021"

1,78,207 including 92,677 are males and 85,530 are females. The percentage of Scheduled Tribe is $1.93 \%$. (Singh \& Kannan, 2018). Tonk district has various manufacturing industries like Namda and Edible oil in Tonk, Vegetable oil in Newai, Slate Stone in Deoli and Stone sculptures of Todaraisingh.

Tonk is a district which is not only a hub for natural sand gravel (Bajri) for real estate in Jaipur (capital of the Rajasthan) but also a major supplier of drinking water from Bisalpur dam to Jaipur, Ajmer and other regions. This dam is based on river Banas. This river is the sub-tributary of the river Yamuna. The Banas River enters into the Tonk district through Negdiya village in Deoli Tehsil. And Negdiya was the largest brothel during 1990s in Tonk district. The remains of this brothel are now submerged in the Banas River, just near the new bridge connecting Deoli to Ajmer.

\section{Theoretical background}

Emotional manipulations are the main instruments for the industry of community basedhuman trafficking networks. Let's take an example of Child Guardianship, initially operating in coordination with family elders or individuals who purchased her after launching a girl in the sex industry. After that, as she starts earning high or falls in touch with some specific client, these individuals start forcing her to give birth to an infant, so that under Child Guardianship they could use the new-born as a tool. Besides, doctoring of perception of girls is carried out by their families through social manipulations and through inducing envy towards other girls and women in the society in the minds of victims. The concern is that these people don't even know they've been abused. Victims often agree to the initial phases of trafficking because the traffickers mislead or betray them. Around the same time, in many nations, civil and other human rights guarantee demand that those accused of trafficking should be able to raise the chance of agreement as a shield.Trafficking prosecutions are sometimes lost because there is no proof available that is required to determine the true essence of the consent. In many instances when law enforcement agencies remain unsuccessful to free trafficked girls from the trafficking web, due to lack of sufficient evidence, delay in the judicial process, this is why culprits remain free by using loopholes of government machinery and by taking advantage of 'Benefit of doubt'. As held in case of Sex trafficking registered under Sections 3, 4, 7 and 8 of Immoral Traffic (Prevention) act 1956, in Deoli police station under FIR number 316/2008, CIS number 1005/2014 and foreclosure number 662/2008.

Trafficking is a complicated problem for growth. This is an economic epidemic, as the vast majority of women trying to flee poverty are drawn into prostitution by a false hope of economic benefits. Trafficking is a health issue, as trafficked women and children are most at risk from HIV infection. It is a gender problem, as patriarchal power structures increase the secondary role 


\section{International Journal of Social Science and Economic Research}

ISSN: $2455-8834$

Volume:06, Issue:02 "February 2021"

of women in society. Finally, it is a civil issue, since the claimants are deprived of their civil rights and have no access to redress for offences committed against them. Trafficking of human beings is a multi-dimensional, profoundly rotten problem and its avoidance is possible if it is resolved by taking into account the civil, social and economic factors associated with it. Without understanding the problems, it is too difficult to go ahead with preventive measures. (Sen \& Ahuja, 2009).

Why does a girl in the Nat and Kanjar communities prefer to pursue prostitution or a bar girl as a profession in their life? By relating this to psychological concepts, we can answer this question to some extent, firstly, because we know that human behaviour is based on the display and the display is the source from which we receive the information. For example, if you see your mother who is a married woman who works at home from 5 a.m. to 11 p.m., and your aunt who is an unmarried sex worker or bar dancer or bar waiter who is always dressed and able to perform. No matter what you ask her because she has money, most likely a girl is going to go to prostitution, not a married life. Similarly, there is an inappropriate ratio of educated and employed males to educated girls in these communities. That's why even after graduation, girls join the sex business. Second, the Groom Dowry system is also known as the Chaari custom, where the groom should have to give marriage token money to the girl's family for marriage. This is one of the main reasons that hinder intra-caste marriage between the two communities. There are also some negligible examples where girls are available for marriage without Chaari. The free Chaari girl is known as Dharam Beti. Rich people use the Dharam beti to give their daughter. Third, the lack of inter-caste marriages between Nat, Kanjar and other Bhantoo communities. The Nat community believes that they originated in the Rajput clan, which is why they call themselves Rajnat, and never give their daughters to other communities. (Singh \& Kannan, 2018) Kanjar girls are accepted as daughters-in-law, but Nat does not marry Kanjar boys from their daughters because they are considered lower in the social hierarchy. (Linda E. Lucas · 2007).

"Now what will happen with education? Such people who became teachers, became Patwari and Bankers etc are in government services. They are also bringing their daughters in this line. It has been years since..... If we give education to our baby girl then what? wedding! Either she doesn't do it herself, otherwise not getting a good boy then other than bringing in this line, is there any way? So, this line can never be closed in life. Even after this we are sending her to schools so that she would.... Just speak a little bit of English... she could manage in this line........."- A Sex worker

Historically, NAT and Kanjar were Nomadic Acrobats, and later their women began performing as dancers in the Royal Courts. Since the late nineteenth century, the status, livelihood, and identity of performers have all deteriorated, with the result that many of them have been engaged 


\section{International Journal of Social Science and Economic Research}

ISSN: $2455-8834$

Volume:06, Issue:02 "February 2021"

in sexual activities and sexualized performance. Groups in rural India have been engaging in sex work for decades. Rajnat community of Rajasthan was a nomadic tribe (now part of the Scheduled Castes category) who had previously been engaged as musicians, actors, street artists, and entertainers of kings, zamindars, and their subjects. However, after the abolition of the monarchy in Rajasthan and the fall of the zamindari regime, Rajnats are left landless and poor but later engaged in commercial sex work. This has resulted in the insecurity, deprivation and marginalization of Rajnats. Girls are coerced and sent to Mumbai and other cities for bar dance at the tender age of 15-16 years. They are not permitted to study more than 8th level, since they may change their minds about not embracing this sex work profession. The Rajnat community is based in many villages of Rajasthan, adjacent to the highways, as this connectivity attracts the rapid influx of customers to the villages. Women and girls in this culture are insecure and are merely the targets of this social activity. This has resulted in the insecurity, deprivation and marginalization of Rajnats. Girls are coerced and sent to Mumbai and other cities for bar dance at the tender age of 15-16 years. They are not permitted to study more than 8th level, since they may change their minds about not embracing this sex work profession. The Rajnat community is based in many villages of Rajasthan, adjacent to the highways, as this connectivity attracts the rapid influx of customers to the villages. Women and girls in this culture are insecure and are merely the targets of this social activity. Experience of physical and verbal abuse is the cause of this culture, which has the largest effects on women and children. Rajnats live a socially isolated life with several peculiar features. (Azeez et al., 2017).

The 'rajnats' or 'nats' were dancers and singers in the royal courts, but they were reduced to complete penury and prostituted by the decline of the feudal order. While most of the girls in the community have been pushed into commercial sex, the men have worked as pimps, and the tradition has continued. Even though commercial sex work has been demolished in most parts of the state, there are patches in which some girls still work since even educated men do not have employment and the scenario is becoming even more critical when it comes to women. (Dhar, 2015). "Bar Girl" is an urban phenomenon and has not been much studied in India. Sex workers can be categorised into six main typologies, based on where they work and more specifically on where they recruit or solicit clients, and not where they live or entertain clients. Bar girls have been categorised as other sex workers,' whose primary occupational identity may vary, but a large proportion of their occupational groups, but not all, often engage in commercial sex on a regular and large scale. Bar girls have also been categorised as Indirect Primary Female Sex Workers (FSWs), which means FSWs who have other sources of income and in particular, solicit clients at their place of work, which are places where the main purpose of facilitating sex work is to facilitate sex work (e.g., massage parlours, bar-based sex workers, singing and dancing girls). Bar girls are also categorised as non-brotherly female sex workers (FSWs-nbb). They don't depend entirely on prostitution. They may or may not have recourse to prostitution. Unlike 


\section{International Journal of Social Science and Economic Research}

ISSN: $2455-8834$

Volume:06, Issue:02 "February 2021"

female sex workers who are brothel-based (FSWs-bb), they have some degree of freedom to practise prostitution. The Family Health International (FHI) behavioural surveillance survey in Maharashtra reported that non-brothel-based FSWs were vulnerable because they were less likely to be accessed through interventions and had less access to condoms or STI treatment. Also there is a shift of male clients from the brothel-based sex industry towards a more informal, non-brothel-based sex exchange, which would be a reason for worry. For HIV/AIDS intervention, the programme must take into account that FSWs working in different settings have various levels of vulnerability and risk of developing sexually transmitted diseases. The study is an effort to reach out to the hard-to-reach core high-risk group and to assess their demographic makeup and sexual behaviour. (Nirgude et al., 2020)

In the meantime, the upper-class women have taken charge of the classical performing arts and have also entered the film industry, while the Bollywood dance and fitness craze has recently swept middle-class India. The rise of unofficial dance environments in the shadow of the formal performing arts of India. About a century of marginalization of courtesans, dancers, bar girls, and transgender artists, defining their lives as they contend with stigmatization, derision, and lack of livelihood.(Thobani, 2015). Gradually, these groups settled on land provided by kings, adopting the subsistence system of agriculture. And to fill the economic crunch created after the end of royal patronage, prostitution began. Initially, their markets were settlements nearby. Gradually, by way of oral ads, their market room has grown. Large-level involvement of the female population in prostitution was a troublesome situation in which the weakness of the female population for marital purposes was viewed in the Nat culture, and later, with all their efforts, a matrimonial alliance with the kanjar people was formed through 'Panchayats.' Kanjar girls are recognised as daughters-in-law, but Nat does not marry Kanjar boys from their daughters because she is regarded lower in the social hierarchy. (Linda E. Lucas · 2007).

Then as the appetite grew, Nat people also began buying girls from the Kanjar community for prostitution. After that, Kanjar was encouraged and motivated by the economic growth of Nats and began prostitution apart from their farming, thieving, and Illegal Liquor activities. One point that needs to be remembered here is that women are like a financial instrument here and that the Kanjar culture has also been a businesswoman for several years. Subsequently, through their clients and other individuals, these groups came to know about urban sex trade markets, such as Major Brothels, Kothas and Dance Bars, etc and moved there. On the other hand, some families from both groups, who felt they could not make it on the commercial market, began the roadsides and the outskirts of urban areas in the disguise of Dhabas (small roadside restaurants) and Agriculture.We may therefore conclude that a subsistence occupation that emerged in the old days is now a transformed version of the rivalry between migrant poor families pursuing higher 


\section{International Journal of Social Science and Economic Research}

ISSN: 2455-8834

Volume:06, Issue:02 "February 2021"

incomes across all kinds of networks where their communities may connect with the target consumer market. (Singh \& Kannan, 2018)

There is a particular collection of causes and consequences for all cases of trafficking. The vast variety of trafficking in persons across regions and cultures means that there can be no standardized solution to the issue. What are the reasons for trafficking? That said there are a variety of commonalities in trafficking. The root causes of trafficking in human beings include the greed of traffickers, economic pressure, political turmoil and transformation, and social and cultural influences. Most smugglers have been implicated in such transnational crimes. Crime organizations tend to trade in persons, partially because they are high-profit and therefore lowrisk, because unlike most goods, individuals can be used repeatedly, and because trafficking in persons does not entail a significant capital investment. (Sarkar, 2016).

Wide-ranging literature analysis and fieldwork have highlighted a range of explanations of why human trafficking practices of this kind have remained hidden from the general public. In the first place, migrants' poor communities are seeking higher wages through human trafficking in the form of agricultural, entertainment, and prostitution disguises. Second, traffic practises are limited to these communities only. And in their dialect, they seldom exchange details with anyone sometimes referred to as 'Kaje.' Finally, these communities resolve disagreements with panchayats, and law enforcement bodies such as the police are the last resort for them, and they also report First Knowledge Details on formal grounds such as Dowry, Domestic Violence, Rape and Robbery, etc. Many who are involved in this form of operation are the highest-pressure groups in these societies who communicate with both civil society and government machinery. Because of these processes, the government is unable to grasp the exact reasons which are responsible for all these activities and their backwardness.

In such a scenario question arises who is poor? According to the World Bank, poverty is a severe lack of well-being that has multiple aspects. It encompasses low wages and the failure to access the basic goods and services required for dignified survival. In India, 21,9\% of the population lived below the national poverty line in 2011. Since Independence, we have created a variety of concepts to define a miracle line that could decide who is bad and lead the blueprints to eliminate this issue. However, in both forums, we had a sour encounter. Even with the global indices MPI, HDI, and Gini Coefficient or unable to solve this problem at any point in time. This is attributable to index plots Figures on the data given by state and non-state agencies, which are mainly collected in India by self-declaration and willingness of the household.

A girl's child is an opportunity here because a woman's feticide is lacking and the sex ratio is fine. If we take an example of the 2011 census data for Village $\mathrm{X}$ in Niwai Tehsil, the total population is 1004 inhabitants, 484 of whom are male and 520 of whom are female. NAT and 


\section{International Journal of Social Science and Economic Research}

ISSN: $2455-8834$

Volume:06, Issue:02 "February 2021"

Kanjar caste belong to the Scheduled Caste in Rajasthan and are registered as resident Scheduled caste community in village $\mathrm{X}$ (Revenue and Food and supply departments, Government of Rajasthan). The total population of the Scheduled caste in this village is 535 people, of which 226 are male and 309 are female. The female population is also 15.5 percent higher than the male population. The estimated number of working people is 488 out of 1004 , which means that $51.3 \%$ of the workforce is unemployed. The non-working male and female demographics were 285 and 231, respectively. Out of the total population of 1004, only 34 per cent (341 persons) is the major working population of which 18 per cent (180) are male and 12 per cent (120) female. Moreover, the key and marginal household sector demographics are zero in all segments, so there are no self-help organisations or cottage industries available. Some which were in operation through NGOs are now closed. Like various projects by World vision, Gram Bharti Samiti etc. are closed now. Hence question emerges how this almost half share of the population lives if they do not have a job and there is no other cottage industry in their villages?

Despite the high priority given to fighting trafficking in human beings by the international humanitarian community, there is still a lack of awareness as to why some people are more vulnerable to trafficking than others. To establish a holistic approach to the issue, knowledge is required not only on the atmosphere in which trafficking exists but also on the understanding and perceptions of vulnerable persons and their populations. Current legal solutions to the sex trafficking crisis also represent a profound inability to discuss the socio-economic root causes of the problem. Since trafficking is viewed as an act (or sequence of acts of abuse, the majority of responses concentrate primarily on punishing smugglers and to a lesser degree, on protecting trafficked individuals. While such methods can account for the effects of trafficking, they appear to ignore the wider socio-economic reality of trafficking of human beings. (Chuang, 2006)

As Varsha Kale, honorary president of the Bar Dancers Association, began fighting for the interests of bar dancers, she acknowledges that she had the same view as the rest of the worldthat these girls had been coerced into the trade, that they had been trafficked, and that they had been abused. However, when I initiated speaking to them, I realised that they had come from the tribes of traditional dancers, that they had joined these bars on their own, and that they had escaped sex work," says Ms Varsha Kale. After the Mumbai dance bars were banned in 2005, they dragged the bar dancers into the vicious trap of destitution and carnage that they were trying to avoid. Astounding $90 \%$ of the dancers came from ethnic tribes that have been traditional artists since the mid-80s. Dancing in the bars of Mumbai was an exit strategy for thousands of women of the Nat tribe who had come from the Tonk district of Rajasthan to Mumbai. In the Tonk district, for example the main centres where Nat community girls pitched tents are Negadia, Deoli Village, Jaisinghpura, and small roadside dwellings on Jaipur-Kota Highway, according to Kanhaiya Puri, secretary of local NGO Grameen Vikas Shodh Avan Takniki 


\section{International Journal of Social Science and Economic Research}

ISSN: $2455-8834$

Volume:06, Issue:02 "February 2021"

Kendra. During her research on the tribes that have traditionally danced for a living, Ms Kale came across references to courtesans in different contexts, the struggle for freedom is one of them. "In our social structure, girls either are retained for marriage or perform," says Rashi, "and then after the ban, the girls were on or the other side of a spectrum - not practised enough to get a good job and separated from the profession of their society. "I hated it, man. I don't want to be a sex worker at all. This is when a girl from my village packed up a bar dancer's job in Mumbai. I asked my family I was heading to go with her. It was after my sister agreed to take care of my daughters that my parents decided to send me," she says. "I went to Mumbai with the lady and remained with her. It was the year of 1990. I washed her house, and I washed her clothes and dishes. She would have asked the bar owners to give me a dance shot, but they found me unappealing. The owner consented one day," said Rinki. (Shivastava, 2016)

By redeploying ancient erotic dances in a globalised India, dance bars have considered as a leading market providing Bollywood-like entertainment with dance, music and hospitality to the new consumer class. The Dance Bar industry supplied job opportunities for poor girls to make a living and demonstrated to be an extraordinary market where women's labour was well reimbursed. By launching their caste capital i.e. the inherited skill sets of dance, drama and sexual use, traditional dance women are taking over and run the market for dance bars. To this extent, bargirls can be seen as a 'performing caste' proceeding their inherited caste occupations in a globalising capitalist market. However, while their relationship with the customer was described through the industry and gained money, fame and wealth through their profession, the bargirls questioned, transformed and reshaped the caste hierarchy by the use of caste capital. (Dalwai, 2012)

In many parts of the globalized world, there has been an escalating conflict with multi-level chaos and anarchy, leading to a massive loss of life, economic slowdown, and most sadly, a sense of community fear and uncertainty. In the Third World, ethnic clashes and communal violence are considered to be equal to the threat of terrorism. The efforts of law enforcement agencies are constantly challenged to resolve community-based conflicts on their own. Emerging conflict resolution models to ensure normative order and community resilience require communities to be their partners. There is an increasing need for the police, as a lawenforcement agency, to transform itself into a community-based agency, given that the field of enforcement is community-based. The pitiful police population ratio in India (106 police personnel per 0.1 million population) has not only overburdened the critical forces but has had a huge impact on their performance. Trafficking in women and children must be seen as refugees and internally displaced persons in a broader context of labour migration and the movement of people from conflict zones and crises. These movements, in turn, interact with gender equality structures at all levels-national and global, in families and communities. An effective analytical 


\section{International Journal of Social Science and Economic Research}

ISSN: $2455-8834$

Volume:06, Issue:02 "February 2021"

and action framework must address these linkages in a serious and coordinated manner. (Sen, 2006).

On 16 July, the Supreme Court upheld the verdict of the Bombay High Court that quashed the order of the State Government prohibiting dance bars in Maharashtra in 2006. Over 350 young women from Shankerpura, Ramnagar, Mohanpura in Bundi District, and Chachoda in Baran District, depended on dancing in Maharashtra bars to survive until the ban was enforced. They're all set to get back to some of what they termed their "glorious days" at the bar." Rajasthan Kanjar Bhatu Samiti said that after the ban Kanjar bar dancers were forced into prostitution but now they will be able to live with dignity. If a particular community is involved in unethical means of earning, there should be many political, economic, social issues must be associated with this. The reopening of dance bars could be a good sign for girls already indulged in this business but this is a worse sign for females who are not introduced in this vicious cycle.(Business line, 2013)

In South Asia, both trafficking and HIV/AIDS occur in a climate of denial and silence at all levels. There is widespread silence about violence against women and girls, in particular domestic violence, and silence about their circumstances, including the abuse and exploitation they often face in their living and working environments in the process of earning a living. This silence manifests itself in the denial in families and communities and in society at large that trafficking in women and girls is taking place. At the same time, there is silence and lack of willingness to recognize that the HIV/AIDS epidemic is a major development challenge and that HIV-positive people are increasingly in our midst and need our care and concern, as well as the observance of human rights. (Shah et al., 2009)

\section{Method}

This paper uses a research approach that allows the researcher to develop a comparative platform for the analysis of district-level quantitative data alongside ethnographic primary data on the subject of research. Since the number of published data related to community-based Human Trafficking or Sex trafficking from Tonk District is much lower, primary data collection includes data sources through empirical methods like field surveys, ethnographic observations, interviews, etc. General data available from secondary sources include censuses, government releases, records, media reports, etc. And for the analysis of data, first, the mapping work was done on spatial data related to the Tonk District, such as the settlements of the Nat and Kanjar communities plotted on the sub-district map of the Tonk District. Second, the graphing of nonspatial data related to communities such as demography, economy, health, etc has been done. Third, thematic mapping has been carried out through the integration of previous work. Finally, the spatial analysis was carried out using statistical tools to develop the scientific relationship 


\section{International Journal of Social Science and Economic Research}

ISSN: $2455-8834$

Volume:06, Issue:02 "February 2021"

between different variables. Interviews of the participants were formulated in the form of transcripts. Some basic issues related to the collection of data on trafficking in human beings could be illustrated as follows: the concealed population, a group for which size and boundaries are unknown and for which there is no sampling framework. Membership in the hidden community often involves stigmatised or unethical activities, leading individuals to refuse to comply or to give inaccurate responses to conceal their identity.

\section{Qualitative methods}

To draw pragmatic conclusions, a qualitative study was first performed to observe phenomenological interviews with stakeholders in the Nat and Kanjar populations of the Tonk district and neighbouring districts, in particular, the Jaipur and Bhilwara districts and various other stakeholders like government officials, NGOs', Media persons (Especially local reporters) and elected representatives of Gram Panchayats and Panchayat Samities among others. The nonprobabilistic Snowball sampling method was used to select a sample of the neighbourhood population. And sampling was started from a settlement named Mohanpura Nattan in Deoli Tehsil. Verbal permission has been received from each interviewee. To preserve the anonymity of the results, the identities of the participants have been updated. In their interviews with the participants, the researcher added questions relevant to the investigation. The average time for each interview was 15 minutes.

\section{Quantitative methods}

Data collected from government releases, records and other organisations. The term 'communitybased human trafficking' remains a building block in literature with multiple interpretations, and there are fewer quantitative studies available to allow for scientific investigation of this construction. The strength of this study is that it builds on intensive fieldwork to advance the knowledge base. Census 2011 data on Tehsil wise population, sex ratio, working and nonworking population, comparative crime analysis between the Tonk district and India, literacy rate and occupational structure of the Tonk district.

\section{Result}

A total of 62 interviews were observed. Of these, 17 interviews were conducted with women engaged in sex work at the time of data collection. The average age at which participants were trafficked ranged from 12 to 23 years. The average level of education ranged from the illiterate to the 8 th grade. The age range of participants was between 20 and 47 years. In terms of religious affiliation, $86 \%$ followed Hinduism, while others said they did not believe in God and had no religious identity. Approximately $78 \%$ of participants reported belonging to the caste schedule in their state of origin. For the participants, trafficking was the result of economic needs that forced 


\section{International Journal of Social Science and Economic Research}

ISSN: $2455-8834$

Volume:06, Issue:02 "February 2021"

their original families to do so. Over $20 \%$ of respondents were HIV-positive and received government-funded medicines. 12 Women who worked in the household were married, and some of their husbands and family members reported that 9 women belonged to Kanjar caste and 3 were Nat caste women.

Based on the data collected, there are trafficking practises in 75 families present. Various issues identified through literature review and fieldwork were later cross-checked through interviews with ethnographic participants. And many unknown facts related to stakeholders, migration patterns, educational trends, economic structure, the Chaari system, Bhantu Panchayat, and psychological tactics, etc., have been discovered. Since 1998 when the first case reported for HIV/AIDS in Rajasthan Various government or non-government entities meticulously tried to develop skill-based Micro, Small, and Medium enterprises among these communities, to give them hope for a better future. However, these projects showed negligible results. Besides, these communities are converting government poverty-scaling programs into sex trafficking infrastructures. As in the case of the then Indira Gandhi Awas Yojana and Pradhan Mantri Awas Yojana, they used government subsidies to create pukka houses for sex trafficking by subsidising even those who are not permanent residents of villages. Apart from this, the Stand-up India program of the Indian government is dedicated to promoting entrepreneurship among underprivileged sections of society. Government considers these sections as priority sectors to give them credit within the timeframe so that potential entrepreneurs could take a risk and commence innovative start-ups. Though, some transient poor communities are taking an immense risk by borrowing credit from an unorganized sector with the rate of interests (around 24\%-36\%) to develop sex trafficking start-ups.

'A girl child is an asset to gain economic wellbeing but a boy is mandatory for property rights and eventually symbolic empowerment, however, nothing has been achieved by all these mindsets"- A sex worker

Interviews with elderly sex workers have revealed a novel but incomplete financial empowerment paradigm called Jamyawadi. Novel because Jamyawadi is a girl or woman who saves for herself or her own family. Incomplete because till now this plan of action persisted unsuccessfully, as sex workers are not adequately aware to invest in safer financial properties. Financial properties like agricultural land, flats, gold, etc are not secure. furthermore, if family interest groups will become aware of the assets, they will forcefully allocate these resources to other male members of the family under a scheme known as the 'Ba-poti custom'. To escape from this situation, Sex worker needs to born with a baby boy. Otherwise, she will remain ' $B a$ poti' of the male family members. This law applies solely to community girls or women. If it is a purchased or kidnapped girl or woman, she is not entitled to get this relaxation. Her whole generation will remain Ba-poti. 'Ba-poti custom is similar to the bounded labour system with 


\section{International Journal of Social Science and Economic Research}

ISSN: $2455-8834$

Volume:06, Issue:02 "February 2021"

some symbolic privileges. The most emphasized privilege is that the married women in their family use to sit on the earth to earn them a sort of honour. Despite many privileges, the women involved are subject to strict rules in their communities. A project called Saksham with a focus on HIV prevention is to help them claim their rights and enhance their social status. Through generations, communities like Nat, Khanjar, Sansi, Banchada, etc. Have been involved in female sex work and their tradition have become a normal element of local society. The community sustains the profession through sex. (Mathur, 2012)

"We can't doubt that some mangrove patches are still alive and struggling to shield girls and women from the very salty sea level of this line (Dhandha)."-Educated Mumbai based dance bargirl.

Recognizing that she had a lot of responsibility on her shoulders as people rested their faith in her, Ranjana's priority is the high school for girls and good roads and sanitation for the villages under her panchayat. "I want to do something for girls' education and for women who are either single or widowed to empower them," she says, adding that educating girls will bring about a major social change. The Rajnat community of Rajasthan, which has been struggling to give up prostitution, has been able to elect a woman as Sarpanch of Jaisinghpura, a woman's reserved post. The eligibility criteria for the sarpanch was eight class passed girl and Ranjana Kamdhar, who finished class 12, was well qualified for this job. The 'Rajnats' or 'Nats' were dancers and singers in the royal courts, but they were reduced to penury and prostituted by the fall of the feudal order. Ranjana's priority is education for girls, because she thinks this can bring about major social change. (Limca book of records, 2018).

\section{Validity and reliability}

The study aimed to conduct a micro-level ethnographic study of the Nat and Kanjar groups, to understand the socio-economic and political dimensions of these communities. Besides, to study and highlight the hidden nature of human trafficking networks developed within and between the communities associated with these communities. As data on trafficking in human beings at the district level is not available from international organizations, qualitative analysis was carried out based on data sets from the Indian and Rajasthan governments. Primary data were qualitatively collected and observed by researchers to explore the depth of the constructions identified by community-based organised human trafficking networks in Rajasthan. Content validity was maintained in the qualitative analysis and the methods of inter-rater reliability were applied while qualitative data were analysed. The results of this qualitative study explain the current human trafficking situation in the Tonk district of Rajasthan. The limitation of such data is that it is not generally applicable.

\section{Conclusion}




\section{International Journal of Social Science and Economic Research}

ISSN: $2455-8834$

Volume:06, Issue:02 "February 2021"

Sex work is a very dangerous occupation. The use of harm minimization principles can help protect the lives of sex workers in the same way that drug users have benefited from drug use harm reduction. Sexual workers are exposed to severe damage: drug use, disease, violence, discrimination, dept, criminalization and exploitation. Successful harm reduction techniques include education, empowerment, preventative measures, care, occupational health, etc.(Rekart, 2005). The pull and push factors cause trafficking in human beings, and these factors are driven by economic factors such as demand and supply. Push factors such as poverty, neglect of the home environment, political instability, etc. could be driving factors, and equally, pull factors such as demand for slave labor could be driving factors in the global market. (Mandal, 2009In the South Asian context, it is hard to separate prostitution from trafficking in human beings (Jani, 2009). Prostitution is a strong taboo in conservative cultures, with women engaged in prostitution being controlled by someone else. From this perspective, it is nothing more than a form of trafficking in human beings. (Jani and falke). Located within its wider context, the issue of trafficking in human beings calls for attempts to tackle this foreign crime and human rights abuses to take seriously the need to resolve its root causes.

Over a decade of multinational counter-trafficking efforts, including a "law and order" solution to the crisis, have produced dubious, if not disappointing, results. The international community is increasingly aware that dealing with trafficking is a major, if not exclusive, concern for border and crime prevention, but only to respond to a snapshot of a much larger problem. No question of tackling poverty, unemployment, discrimination and gender-based violence, among other factors that increase the vulnerability of individuals to trafficking, is a major challenge that calls for creative and long-term strategic thinking.There is no doubt that tackling hunger, unemployment, sexism and gender-based harassment, among other causes that raise people's exposure to trafficking, is a major challenge that needs innovative and long-term strategic thinking. The revised anti-trafficking bill sets out steep fines and proposes "mandatory reporting" of trafficking offences, which makes it a felony if an individual is aware of a misdemeanour but withholds it from the authorities. One point that needs to be remembered here is that families are central actors in community-based sex and bride-trafficking networks in these communities, and generalised solutions are not relevant to this situation. The need for an hour is then a group and a problem-oriented solution. This paper aims to raise awareness of the crisis, realities, victims, and stakeholders involved in community-based sex trafficking networks. So that we can begin to talk about this problem and generate ideas about how we can do things better and prevent this kind of behaviour.

\section{References}

A 'Tradition' In Rajasthan Pushes Daughters into Prostitution - Everylifecounts.NDTV.com. Everylifecounts.NDTV.com. (2016). Retrieved 12 December 2020, from 
International Journal of Social Science and Economic Research

ISSN: 2455-8834

Volume:06, Issue:02 "February 2021"

https://everylifecounts.ndtv.com/a-tradition-in-rajasthan-pushes-daughters-into-prostitution$\underline{7623 .}$.

Azeez, E., Toolsiram, R., \& Mishra, A. (2017). Rajnats of Rajasthan and the Sex Work: An Ethnographic Study. Contemporary Voice of Dalit, 9(1), 37-47.

Business line, T. (2013). Kanjar women all set to resume dancing in Mumbai bars again. @businessline. Retrieved 12 December 2020, from

https://www.thehindubusinessline.com/news/kanjar-women-all-set-to-resume-dancing-inmumbai-bars-again/article20639257.ece1.

Chuang, J. (2006). Beyond a Snapshot: Preventing Human Trafficking in the Global Economy. Indiana Journal of Global Legal Studies, 13(1), 137-163.

Dalwai, S. (2012). Performing caste: the ban on bar dancing in Mumbai. Ethos.bl.uk. Retrieved 12 December 2020

Dhar, A. (2015). 'Rajnat' girls unable to quit flesh trade. The Hindu. Retrieved 12 December 2020, from https://www.thehindu.com/news/national/rajnat-girls-unable-to-quit-fleshtrade/article6996658.ece.

Dhar, A. (2016). First 'Rajnat' woman sarpanch. The Hindu. Retrieved 12 December 2020, from https://www.thehindu.com/news/national/first-rajnat-woman-sarpanch/article6996659.ece.

Limca book of records. (2018). A Rajnat Becomes Sarpanch. The Coca-Cola Company. Retrieved 12 December 2020, from https://www.coca-colaindia.com/stories/a-rajnat-becomessarpanch.

Lucas, L. (2007). Unpacking globalization. Lexington Books.

Mandal, S. (2009). Trafficking in Women and Children: A Socio-Legal Challenge. SSRN Electronic Journal. https://doi.org/10.2139/ssrn.1701925

Mathur, A. (2012). Empowering rural traditional sex-workers in Rajasthan. Rural21.com. Retrieved 12 December 2020, from https://www.rural21.com/english/news/detail/article/empowering-rural-traditional-sex-workersin-rajasthan.html.

Mittal, H. (2019). 'ऑपरेशनगुड़िया' काअसर: मुख्यआरोपीगिरफ्तार, 2

लड़कियांनिकलीदलालोंकेचंगुलसे. Zee Rajasthan. Retrieved 12 December 2020, from https://zeenews.india.com/hindi/india/rajasthan/impact-of-operation-gudia-main-accussedarrested-2-girls-rescued/559048. 


\section{International Journal of Social Science and Economic Research}

ISSN: $2455-8834$

Volume:06, Issue:02 "February 2021"

Nirgude, A., Solanki, M., Shinde, R., \& Naik, P. (2020). Study of sexual behaviour of bar-girls residing in an urban slum area of Mumbai. Retrieved 12 December 2020.

Pandey, D. (2015). Community Policing and Women Safety in India. International Journal of Humanities \& Social Science Studies (IJHSSS), Volume-II(Issue-II), 229-239. Retrieved 12 December 2020.

Ray, N. (2008). Vulnerability to Human Trafficking: A Qualitative Study. Washington University Open Scholarship. Retrieved 12 December 2020,

Rekart, M. (2005). Sex-work harm reduction. The Lancet, 366(9503), 2123-2134. https://doi.org/10.1016/s0140-6736(05)67732-x

Sarkar, S. (2016). Child Marriage Trafficking in India: Victims of Sexual and Gender-Based Violence. Anthropology Now, 8(3), 62-70.

Sen, S., \& Ahuja, J. (2009). Trafficking in women and children: Myths and realities. https://sherloc.unodc.org/. Retrieved 12 December 2020, from https://sherloc.unodc.org/cld/bibliography/2009/trafficking_in_women_and_children_myths_and _realities.html.

Sen, P. (2006). Combating Trafficking of Women and Minors With the 4 Rs. SSRN Electronic Journal.

Shah, V., Brar, B., \& Yangchen Rana, S. (2009). Layers of Silence: Links between Women's Vulnerability, Trafficking and HIV/AIDS in Bangladesh, India, and Nepal | Publications | UNRISD. Unrisd.org. Retrieved 12 December 2020https://www.unrisd.org/unrisd/website/document.nsf/(httpPublications)/B4D9538DE438A5 F3C1256BB900324E59?OpenDocument.

Shivastava, R. (2016). Dancing to fate's tune. The Hindu. Retrieved 12 December 2020, from https://www.thehindu.com/news/cities/mumbai/a-ban-that-has-pushed-them-to-themargins/article8399983.ece.

Sharma, A. (2016). Sex Workers Defy Tradition: "Our Daughters Will Not Be Prostitutes, They Will Study.". The Better India. Retrieved 12 December 2020, from https://www.thebetterindia.com/54687/sex-workers-prostitution-rajnat-rajasthan-daughterseducation/.

Singh, M., \& Kannan, M. (2018). AGRICULTURE WITH PROSTITUTION, A CANOPY OF ORGANISED HUMAN TRAFFICKING WEBS IN TONK DISTRICT OF 
International Journal of Social Science and Economic Research

ISSN: 2455-8834

Volume:06, Issue:02 "February 2021"

RAJASTHAN. International Journal of Social Science and Economic

Research, Volume:03(Issue:08), 4406- 4418. Retrieved 13 December 2020,

Thobani, S. (2015). Morcom, Anna. Illicit worlds of Indian dance: cultures of exclusion. xii, 286 pp., illus., bibliogr. London: C. Hurst \& Co. Ltd, 2014. £20.00 (paper). Journal of The Royal Anthropological Institute, 21(4), 937-939.

WDR-2010. United Nations: Office on Drugs and Crime. (2020). Retrieved 12 December 2020, from 